\title{
Clostridial brain abscess and hyperbaric oxygen
}

\author{
A. J. KEOGH* \\ M.B.(Glas.), F.R.C.S.(Eng.) \\ South-East Metropolitan Regional Neurosurgical Unit, Brook General Hospital, London SE18 4LW
}

\begin{abstract}
Summary
The first case of 'gas gangrene' of the brain treated with hyperbaric oxygen is reported. It is suggested that there is no place in clostridial infection confined to the central nervous system for hyperbaric oxygen treatment. The early onset of symptoms in clostridial brain abscess with the presence of a gas bubble localizing the abscess were again confirmed. The importance of taking a careful history and obtaining skull radiographs in suspected penetrating wounds is stressed.
\end{abstract}

\section{Introduction}

Gas gangrene infection is uncommon, but usually carries a high morbidity and mortality, because traumatized or devitalized tissue provides a suitable culture medium for the clostridia to multiply and produce the toxins which destroy the host cells. It is more common in war-time practice, because treatment is delayed and high velocity missile injuries can produce extensive tissue damage by 'cavitation' (Thoresby \& Watts, 1967).

Clostridia are widely distributed, causing contamination in many wounds, but only a few develop infection; in the Western Desert (1940-42) MacLennan (1943) found that $20-30 \%$ of all wounds became contaminated, but only $0.32 \%$ of these developed gas gangrene. A study of 125 cases of head wounds sustained in the El Alamein line (1942) revealed twenty-six cases contaminated with clostridia, but not a single case developed gas gangrene (Ashcroft \& Pulvertaft, 1947).

Cairns et al. (1947) classified clostridial brain infections after wounding into four groups, viz:

(1) Large dirty suppurating brain wounds.

(2) Abscesses arising from small to average penetrating wounds.

(3) Mild superficial infections.

(4) Clostridia present in the CSF.

\section{Case history}

A 7-year-ord West Indian girl attended her local casualty department with a story of having been struck on the head with a piece of wood. She had not been unconscious. She was found to have a small contused scalp wound in the right frontal region,

* Present address: Department of Neurological Surgery, Royal Inflrmary, Sheffield S6 3DA. which required one stitch. She was given a booster dose of tetanus toxoid and was asked to report later for removal of the stitch.

Subsequently it was learned that the piece of wood in question was a beam $1.65 \mathrm{~m}$ long, weighing approximately $6.75 \mathrm{~kg}$, at the end of which a rusty nail protruded about $5 \mathrm{~cm}$. The patient had been sitting beside a friend who had lifted one end of the beam and it had slipped and fallen about $0.45 \mathrm{~m}$ onto the girl's head.

She was brought back to the casualty department on the third day after her injury because of persistent headache, vomiting and drowiness. When examined, she had a temperature of $104^{\circ} \mathrm{F}$, together with neck stiffness and a positive Kernig's sign. Radiography showed a depressed flake of bone with an associated air bubble (Fig. 1a and b). She was admitted and lumbar puncture gave the following results: CSFO protein $50 \mathrm{mg}$, sugar $10 \mathrm{mg} / 100 \mathrm{ml}, 3$ lymphocytes $\mathrm{mm}^{3}, 36 \mathrm{RBC} / \mathrm{mm}^{3}$. Blood: Hb $11.8 \mathrm{~g} / 100 \mathrm{ml}$, WBC6 $23,000 / \mathrm{mm}^{3}$ of which 20,400 were neutrophils. She was treated with intravenous chloramphenicol, penicillin and sulphadiazine. The following day, in addition to persistent fever and signs of meningism, she was found to have a left hemiplegia and was referred to the Regional Neurosurgical Unit.

On admission she was found to be drowsy, but able to complain of headache. She looked ill, had marked neck stiffness, a fever of $103^{\circ} \mathrm{F}$, and in the

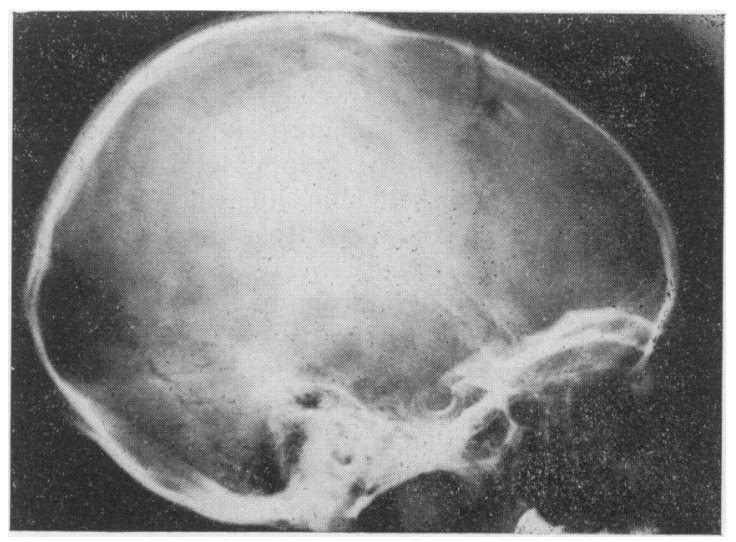

FIG. 1a. 


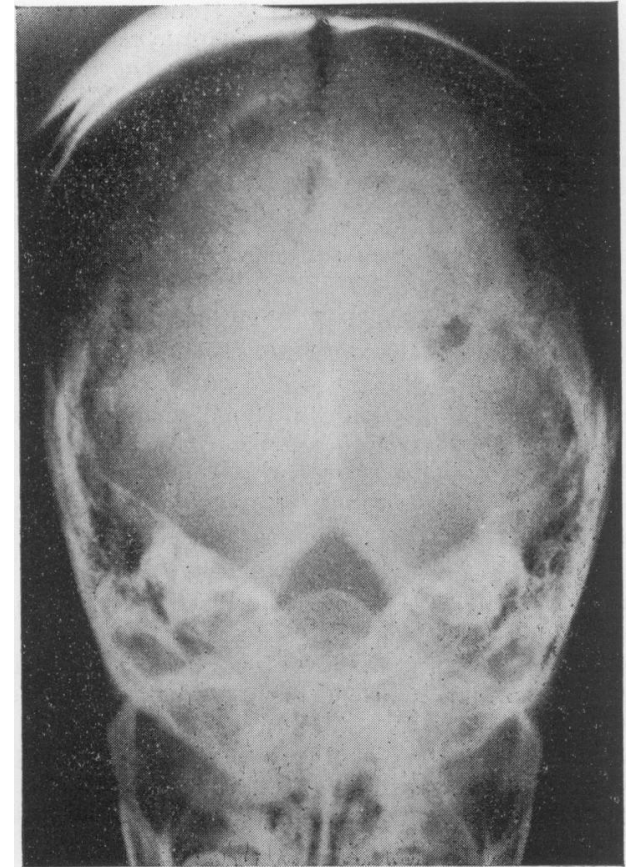

Fig. 1b. Skull X-rays showing a loose flake of bone and an associated gas shadow in the frontal region.

right frontal region a small sutured wound with marked surrounding cellulitis. Examination of the central nervous system revealed a severe flaccid left hemiplegia involving her face, arm and leg, and possibly a left homonymous hemianopia.

At operation, on removing the suture, bubbles of gas were seen to escape from the stitch holes, together with a small amount of pus. A skin flap was made to reveal a puncture wound in the skull conforming to the diameter of the nail in the beam, below which was found a loose flake of inner skull table with a $4 \mathrm{~cm}$ track into the brain. The track contained thin watery pus. A swab was taken. A pure culture of Clostridium welchii was subsequently grown. Removal of the loose bone fragment and excision of the track was carried out and the wound closed. In the following $24 \mathrm{hr}$ her temperature settled and remained normal throughout the rest of her illness; she also became more alert, but there was no change in her hemiplegia.

On the second postoperative day she was referred to another hospital for hyperbaric oxygen and received $20 \mathrm{hr}$ treatment, equivalent to $100 \%$ oxygen at 20 p.s.i., in divided dosesover the following 5 days. No change was noted on return to the Neurosurgical Unit on the seventh postoperative day. Over the next 2 days she became lethargic, and a fluctuant swelling was noted below the skin flap. Nine days after her original operation, further exploration was performed. The fluctuant swelling was found to be brain extruding from the skull with an underlying abscess cavity measuring approximately $4 \times 2 \times 1 \mathrm{~cm}$ containing yellowish-green pus. This was evacuated and a tube put into the cavity to instil local penicillin. Culture from this pus again revealed Clostridium welchii.

Within $24 \mathrm{hr}$ she began to move her left leg.

Over the next 10 days local penicillin was administered into the abscess cavity and occasional aspirations of small amounts of pus performed. After a further fortnight she was allowed home, walking well. Two months later she was very well with only slight weakness in the extensors of her left wrist and fingers, and a full recovery was anticipated.

\section{Discussion}

Intensive systemic antibiotics had been started before referral to the Regional Unit, and these were continued. The initial operative treatment was scalp excision and removal of necrotic brain in the track. Gas-forming organisms were suspected. Two days later, when the presence of Clostridia was proved, hyperbaric oxygen therapy was instituted. In spite of this therapy, an abscess formed in the track, which was subsequently treated by aspirations and local antibiotics, together with continued systemic antibiotics, the combination bringing the abscess under control. Anti-gas gangrene serum was not used.

Cairns et al. (1947) reported five cases of intracerebral clostridial brain abscess from penetrating wounds, and concluded that although the abscess tended to become established unusually early after wounding, it was remarkably benign. They noted that even in the extremely severe wounds in which the Clostridia were found (in association with other organisms) there was no evidence of clostridial infection spreading through healthy brain and no clinical indication of toxaemia, except when temporal muscle was involved.

Inhibition of clostridial growth (and, therefore, reduction of toxin production) is brought about by raising the tissue oxygen tension: the spread of the disease is halted and toxaemia controlled (Brummelkamp, Boerema \& Hoogendyk, 1963). Hyperbaric oxygen is an established adjunct in the treatment of gas gangrene elsewhere in the body-all authors emphasizing that necrotic tissue must still be excised. 'Gas gangrene' in the brain has little tendency to spread and toxaemia does not appear to be important; hyperbaric oxygen, therefore, probably has no part in the treatment.

Nineteen well documented cases of circumscribed gas gangrene (clostridial) abscess of the brain have been reported: eleven from civilian practice (three 
of which developed the infection secondary to middle ear disease), and eight cases from military practice. Four of these cases died (two before antibiotics), none of those secondary to ear disease died; and in the cases of wounding, all had symptoms within 7 days (commonly after $24-48 \mathrm{hr}$ ) and in ten out of fourteen, X-ray films showed a bubble of gas accurately localizing the abscess site (Cairns et al., 1947; Clarke, 1968; Gilbert, Tolmach \& Farrell, 1961; Heineman \& Brande 1963; Morello \& Betinazzi, 1966; Russell \& Taylor, 1963).

This case illustrates the importance of taking a careful history and eliciting details of the accident with particular reference to the weight and size of the 'weapon' involved, even going to the extent of procuring the offending object with a view to measuring the depth of penetration. The patient's father in this case measured the length of the beam and sawed off the appropriate end.

Most authors agree that in view of the risks of serum sickness and hypersensitivity, anti-gas gangrene serum has no place in the prevention or treatment of gas gangrene in any situation (Johnson, Gillespie \& Cole, 1969; Schraibauan, 1968; Slack, Hanson \& Chew, 1969).

\section{Acknowledgment}

I would like to thank Mr G. B. Northcroft, M.B.E., F.R.C.s. for his encouragement and helpful advice, and for his permission to publish this case.

\section{References}

Ascroft, P.B. \& Pulvertaft, R.J.V. (1947) The bacteriology of head wounds. British Journal of Surgery (War Surgery Supplement), 1, 183.
Brummelkamp, W.H., Boerema, I. \& Hoogendyk, L. (1963) Treatment of clostridial infection with hyperbaric oxygen $\vec{s}$ drenching. A report on twenty-six cases. Lancet, i, 235.

Cairns, H., Calvert, C.A., Daniel, P. \& NorthCroft, G.B. $\complement$ (1947) Complications of head wounds with special reference to infection. British Journal of Surgery (War $\stackrel{\text { S }}{+}$ Surgery Supplement), 1, 198.

ClaRKe, P.R. (1968) Gas gangrene abscess of the brain. $\bar{\sigma}$ Journal of Neurology, Neurosurgery and Psychiatry, 31, $\bar{\Phi}$ 391.

Gilbert, A.I., TolmaCh, R.S. \& Farrell, J.J. (1961) Gas gangrene of the brain. American Journal of Surgery, 101, $\infty$ 366.

Heineman, H.S. \& Brande, A.I. (1963) Anaerobic infection of the brain. Observations on eighteen consecutive cases $\vec{\omega}$ of brain abscess. American Journal of Medicine, 35, 682.

Johnson, J.T., Gillespie, T.E. \& Cole, J.R. (1969) Hyperbaric oxygen therapy for gas gangrene in war wounds. 3 American Journal of Surgery, 118, 839.

MaCLenNan, J.D. (1943) Anaerobic infection of war wounds in the middle ear. Lancet, ii, 123.

Morello, A. \& Betrinazzi, N. (1966) Brain abscess due to gas bacillus infection. Report on a case. Journal of Neuro- + surgery, 24, 752.

Russell, J.A. \& TAYLOR, J.C. (1963) Circumscribed gas gangrene abscess of the brain. Case report together with $c$ an account of the literature. British Journal of Surgery, 50, 434.

Schraibrauan, I.G. (1968) Anti-serum in gas gangrene. British Medical Journal, 1, 704.

Slack, W.K., Hanson, G.C. \& Chew, H.E.R. (1999 Hyperbaric oxygen in the treatment of gas gangrene and clostridial infections. A report of 40 patients treated in single-person hyperbaric oxygen chamber. British Journäl of Surgery, 56, 505.

Thoresby, F.P. \& WaTts, J.C. (1967) Gas gangrene of the high velocity missile wound. British Journal of Surgery, 56, 요 25. 